\title{
Tradición e identidad en la conformación de la sociedad chilena
}

\author{
Pablo Rivera Vargas*
}

RESUMEN

La construcción de una sociedad se hace no sólo evaluando el presente o planificando el futuro. Un ejercicio natural que la mayoría de las sociedades desarrolladas ya ha realizado, ha sido indagar sobre qué tipo de tradiciones y costumbres que van surgiendo en el tiempo, se van poco a poco asimilando, y cómo estas a la larga condicionan la forma en que los países se enfrentan a los nuevos desafíos de la modernidad. En el caso de Chile, no existe un consenso respecto a qué rasgos tradicionales nos conforman como sociedad, incluso muchos se han atrevido a decir, dada esta situación, que somos un país sin identidad.

El presente artículo es una reflexión que busca aportar al debate antes planteado, a través de una revisión de la bibliografía que existe al respecto en nuestro país. Si bien no se sostiene una tesis final respecto de la problemática, se plantea un estado de la situación.

Palabras clave: Tradición - cultura - armonía social - modernidad

\section{Tradição e identidade na conformación da sociedade chilena}

\begin{abstract}
RESUMO
A construção de uma sociedade, faz-se não só avaliando o presente ou planificando o futuro. Um exercício natural que a maioria das sociedades desenvolvidas já realizou, foi indagar sobre que tipo de tradições e costumes que vão surgindo no tempo, se vão pouco a pouco assimilando, e como estas à longa condicionan a forma em que os países se enfrentam aos novos desafios da modernidad. O caso de Chile, não existe um consenso com respeito a que rasgos tradicionais nos conformam como sociedade, inclusive muitos se atreveram a dizer, dada esta situação, que somos um país sem identidade.
\end{abstract}

Palavras chave: Tradição - cultura - harmonia social - modernidad

* Chileno. Sociólogo. Magíster en Ciencias Sociales. Docente Departamento de Trabajo Social Universidad Católica Silva Henríquez.

Correo electrónico: riveravargaspablo@gmail.com 


\section{Tradition and identity in the formation of Chilean society}

\section{ABSTRACT}

The building of a society is done not only by evaluating the present or planning the future. A natural exercise that the majority of developed societies have already realized has been to inquire about the type of traditions and customs that surge through time, assimilating little by little, and how these end up conditioning the form in which countries confront the new challenges of modernity. The case of Chile in this sense is garish, considering that a consensus doesn't exist with respect to which traditional features lead us to conform as a society, in fact many have dared to say, given this situation, that we are a country without identity.

The present article is a reflection that looks to support the debate raised beforehand through an exhaustive revision of the bibliography that exists with respect to our country. Even if a final thesis cannot sustain itself in regards to the problem, at least the state of the situation will be discussed, which will eventually allow for an organized continuation of the current presentation.

Key Words: Tradition - culture - social harmony - modernity 


\section{Antecedentes}

Nos encontramos en un escenario prolífico para la reflexión académica sobre la trascendental temática del "nosotros social", dado el próximo e inminente contexto "Bicentenario que vivi(re) mos". Por lo mismo, analizar la génesis de la identidad social, en conjunto con nuestras tradiciones, resulta fundamental para determinar el escenario inicial en el que se posiciona el proceso de modernización en nuestro país.

En función de lo anterior y para adentrarnos en esta reflexión, podemos mencionar lo planteado por Giddens (1998), quien sostiene al respecto que una sociedad muy afianzada a sus tradiciones, con un rol activo de los guardianes de las mismas y una reproducción permanente de los rituales por parte de la comunidad, se transforma en una sociedad difícilmente permeable a la implantación de modelos sociales exógenos. Por otro lado, aquellas sociedades que no identifican claramente sus tradiciones y por lo tanto, no tienen un vínculo estrecho hacia ellas, sí resultarían permeables a la implantación de este tipo de modelos.

Para comenzar podemos plantear que la discusión y la búsqueda de información respecto a las tradiciones resulta en más de algún sentido compleja. Con esto intentamos decir que no se establece con absoluto consenso, cuáles son nuestros rasgos tradicionales. Según Garretón (1994) esto tendría relación con una tarea inconclusa de nuestra sociedad respecto a pensarnos como país y a definir nuestros rasgos identitarios.

Por lo tanto, se propone una línea de reflexión sustentada en el intento de debatir (y no establecer) qué aspectos forman parte o no de nuestras tradiciones en Chile.

\section{Debate sobre la identidad Chilena: En búsqueda de las tradiciones}

Indagar sobre quiénes somos los chilenos en el concierto latinoamericano y mundial, significa justificar de alguna forma nuestro pasado y nuestro presente, pero sobre todo es responder a la pregunta: ¿qué hemos deseado ser como país? Esto último es parte fundamental del debate. 
Para Larraín, la identidad es un conjunto de bienes culturales que permiten distinguir una sociedad de otra, y cuyo origen es preferentemente histórico. Tal identidad es propia de los sujetos y no impuesta desde afuera, por tanto, nace de un auto-reconocimiento de la pertenencia a un grupo humano en particular y de toda la herencia que de éste se adquiere. El autor agrega que el proceso de construcción de la identidad cultural, debe entenderse como "algo que no se detiene ni puede detenerse en alguna etapa supuestamente privilegiada, es más, debe comprenderse como un proceso discursivo que permite una variedad de versiones" (Larraín 1994: 84).

Larraín plantea que existen períodos en los cuales el tema de la identidad aflora con inusitada relevancia. Estos momentos coinciden con etapas de cambio y de crisis en nuestras sociedades. Para el caso de Latinoamérica, detecta al menos cuatro momentos bien diferenciados (Larraín 2004)

- El momento de la conquista y colonización de América.

- El surgimiento de los Estados nacionales a principios del s. XIX.

- Durante el período de entreguerras (1919-1930).

- A fines de la década de los sesenta y el fin de los regímenes populistas en América Latina.

Estas cuatro coyunturas habrían dado origen a respuestas diferentes en torno al tema de la identidad. La crisis social y política es entonces, un catalizador de la pregunta sobre las características de nuestra cultura (obviamente asumiendo que compartimos un origen común). Por tanto, las respuestas existentes para estas cuatro coyunturas, constituyen un pensamiento sociopolítico respecto a las características de su propia sociedad, y el anhelo de configurar una identidad acorde con este pensamiento. Resulta de todo esto que la pregunta por la identidad no es un cuestionamiento puramente especulativo, sino que también corresponde a una variante no explícita de pensamiento político, y en algunos casos también de respuesta ideológica ante los problemas de la sociedad y la cultura. Incluso por medio de esta temática, se abordan problemas como el del autoritarismo político y los problemas de la modernización en nuestro continente:

“Del encuentro original entre la cultura española e indígenas, emergió un nuevo modelo cultural fuertemente influenciado por la religión 
católica, íntimamente relacionado con el autoritarismo político y no muy abierto a la razón científica. Este modelo coexistió fácilmente con la esclavitud, el racismo, la inquisición y el monopolio religioso" (Larraín 1994: 40).

Siguiendo el patrón de análisis de este autor, nos encontraríamos en una quinta etapa de cuestionamiento sobre nuestra identidad; etapa que está marcada por los procesos de modernización acelerada que ha vivido nuestro continente desde fines de los años ochenta (neoliberalismo, democracia, redefinición del Estado, etcétera) hasta el día de hoy. La influencia de la cultura norteamericana, la globalización, el cambio tecnológico y la nueva sociedad del conocimiento, presentan una serie de nuevos desafíos para nuestros países, pero a la vez nos vuelve hacia la pregunta de quiénes somos y qué queremos ser:

“El agotamiento de los sueños de industrialización y modernización rápida en los 60, el colapso de los sueños de independencia económica y socialismo ahogados en un mar de sangre en los golpes militares de Brasil en 1964, Argentina en 1966 y 1976, Uruguay y Chile en 1973, y los años bajo terribles dictaduras de derecha, necesariamente pusieron una vez más en el tapete la pregunta acerca de la verdadera identidad latinoamericana y de la naturaleza de las teorías que habían inducido esos sueños" (Larraín 1994: 48).

Actualmente la discusión en torno al tema de la identidad se centra en torno a dos posiciones teóricas: La primera (esencialista) plantea que existe una esencia latinoamericana en nuestro pasado histórico, la cual se encuentra congelada en el mundo indígena o bien en una fusión mestiza originada en el Barroco americano del siglo XVII. Por otro lado, existe también una corriente de pensamiento que destaca el carácter problemático de la identidad, situándola como una constante búsqueda en la cual conviven las diferentes herencias culturales que hemos recibido y continuamos absorbiendo.

Los estudios "esencialistas" son cuestionados por Larraín, ya que parten del supuesto de que los problemas actuales de América Latina podrían resolverse con una vuelta a los valores y prácticas de comunidades indígenas o mestizas; existe una esencia o matriz cultural sepultada y olvidada que hay que recuperar. Las posiciones esencialistas adoptan dos vertientes: una que rechaza el carácter híbrido de nuestra cultura, resaltando su veta hispánica, indígena 
o racionalista (Bengoa), y otra que reconociendo la fusión, fija la identidad en un cierto período de nuestra historia (Morandé).

Para Larraín, los escritores esencialistas, persiguen la idea de que el futuro de Chile y de Latinoamérica depende de su lealtad para con algunas antiguas tradiciones o principios indígenas o mestizos, los que fueron olvidados por la razón instrumental, la élites "alienadas", y por los intentos modernizadores neoliberales. Sin embargo, Larraín otorga a Morandé (1990) la singularidad de haber elaborado una tesis que prioriza los elementos de fusión español-indígena, más que la relación dominador-dominado, que claramente identifica a la corriente neoindigenista. Pero, de todas maneras, cae en la tentación de congelar la identidad latinoamericana en un punto de la historia determinado por el surgimiento de un ethos mestizo oral-religioso. El error, según Larraín, estaría en considerar que todo aquello que sucedió después de la independencia americana (1810), constituye un proceso de alienación racionalista que no hizo más que atentar contra la verdadera estructura del "ser americano". Es decir, nuestra historia sociopolítica contemporánea es parte de nuestra identidad, con sus fracasos e ilusiones, e incluso determina mayormente nuestra cultura que un pasado remoto casi mítico.

A continuación, centraremos la reflexión de las tradiciones y de la identidad chilena, en función del análisis de variables centrales, analizadas por distintas fuentes de información teóricas, relevantes a la hora de establecer las bases de la conformación de la sociedad chilena.

\section{La imitación como rasgo tradicional en la construcción de la sociedad chilena en los siglos XIX y XX}

Existe un consenso sociohistórico a la hora de sostener que Chile se construyó como país, a partir de la imitación de modelos occidentales y no de la construcción de un orden social en función de todos los rasgos culturales propios de la sociedad del siglo XIX.

Al respecto, Morandé sostiene que "son las elites de la época (principios del siglo XIX) las que toman la decisión unilateral de construir la sociedad a nivel constitucional y jurídico tal cual deja el legado de la colonización española en Chile" (Morandé 1990: 
85). Esto se habría dado con el fin de sacar dividendos que sólo favorecieran a los grupos de criollos y europeos, dejando en vilo a la ciudadanía mestiza e indígena. En este sentido, fue más bien la incapacidad de los dirigentes de la época la que los llevó a la imitación. En el PNUD (2002) se sugiere que esta imitación se da por el miedo o incertidumbre que genera el proceso de independencia del país, "por lo que la clase dirigencial de la época opta por mantener el orden legal y jurídico establecido en la colonia, y así evitar el desorden" (PNUD 2002: 78). Bengoa (1996) va más allá y considera que es justamente en este hecho donde se legitima la sociedad de clases en Chile, paradójicamente desde su inicio como país e históricamente privilegiando a las elites. "Su comprensión respecto a cómo construir una sociedad posibilitó que fueran (las elites) quienes se beneficiaron por sobre el resto de la población. Mestizos e indígenas tardaron años en comprender el sentido y lógica de esta organización social" (Bengoa 1996: 120).

Si bien, el sustento de esta afirmación de carácter hipotético, es básicamente subjetivo, podríamos decir, que en gran medida existe un consenso en afirmar que la imitación fue un rasgo tradicional de la época en Chile (Siglo XIX), en la formación de un Estado legal constitucionalmente, lo que a la vez facilitó la estabilidad y el orden social.

Sin embargo, donde surgen los disensos entre las fuentes de información, es respecto a la trayectoria histórica de la acción imitativa de nuestra sociedad. A juicio de Larraín, por ejemplo, la imitación solamente cambia de modelo, pero siempre se mantiene, "durante el siglo XIX hacia Francia y España, y en el siglo XX a Reino Unido y USA" (Larraín 2004: 134). Complementando a esto, Bengoa plantea que esta imitación, que en principio se da en la formación del Estado, en el tiempo termina siendo parte de las más diversas y variadas aristas de la sociedad, estructural y comunitaria, seguiría una especie de "cultura de la imitación", que se sustenta en la idea de que lo mejor está afuera, en Occidente, y que por lo tanto "debemos permanentemente luchar por parecernos a ellos (sociedad occidental capitalista)" (Bengoa 1996: 145).

En una posición contraria, Garretón sostiene que la imitación "solo se puede ver en una fase de nuestra historia, ya que en el desarrollo y evolución de las sociedades predominan los sucesos históricos 
internos" (Garretón 2005: 38), es decir, Chile sí se construye en base a la imitación, pero desde mediados y fines del siglo XIX y todo el siglo XX, todos los sucesos sociales serían consecuencias de fenómenos internos en nuestra sociedad, no externos. La vida social por tanto, toma vida propia y no sería adecuado acomodarla permanentemente y con exactitud a lo que externamente se sugiere. Finalmente Garretón plantea que por más imitación que pueda haber, los resultados de la implantación de un modelo externo en determinada sociedad nunca serán homogéneos, producto del componente cultural.

El PNUD de 1998, complementa la postura de Garretón, al plantear que lo que mueve a Chile a lo largo de su historia, esencialmente es la búsqueda del orden y evitar el caos social y que la imitación es más bien una herramienta para lograr el orden.

Si tomamos la idea de que la imitación es un rasgo histórico y distintivo en la construcción de nuestra sociedad "y que sólo cambia el modelo a imitar, no la acción de hacerlo", y considerando la emergencia de una “cultura de la imitación" y lo también sugerido en el PNUD (1998), en función de que nuestra sociedad, en la búsqueda del orden "está dispuesta a todo", inclusive a imitar, nos damos cuenta que en chile, se presenta un escenario propicio a la instauración de un modelo social exógeno, como es la conceptualización de la modernización en el lenguaje y acción occidental. Por ahí pasaría la trascendencia de considerar a la imitación como un rasgo tradicional.

\section{El Estado como imaginario social del orden y la estabilidad}

Este es uno de los hábitos donde surgen las mayores coincidencias reflexivas y analíticas entre las distintas fuentes consultadas. Lo planteado por Garretón, bien define y representa al resto de los informantes: "ningún país latinoamericano parece tan marcado como Chile, por su matriz Estado céntrica” (Garretón 2005: 43).

El Estado es un elemento que incluso se superpone a la soberanía ciudadana según el PNUD (1998), al plantear que su legitimidad radicaría en la importancia que tiene la soberanía sobre el territorio nacional y eso induciría a la población hacia la cohesión social y la identidad colectiva. Garretón añade que la ciudadanía estaría orgullosa de lo chileno, es decir, la identidad política estatal 
"hacia afuera", nos unifica como país, ya que nos permite sentirnos distintos y a la vez superiores al resto de los países latinoamericanos "la ciudadanía chilena, está orgullosa de su Estado y de su historia, lo que más le importa es que exista y que funcione; sólo hay una excepción de 17 años, cuando se rompe la matriz sociopolítica, que luego se reestructura" (Garretón 2005).

Lo anterior nos sugiere la idea de que el Estado (y las elites que lo conforman) cuenta con cierta libertad civil, para elegir cómo proceder y cómo se estructura, lo que explica el hecho de que gran parte de las decisiones que se tomaron en el siglo XX, y en la actualidad (modelo económico, jurídico, político, camino hacia la modernización) no sean del todo asimiladas por ella.

En el PNUD (2002) se habla de la presencia de un alma estatal, cuya existencia ha sido en el tiempo garantía de orden y estabilidad, con salvedad, desde luego, del período de la dictadura militar. Dicha centralidad del Estado en las sucesivas configuraciones de la sociedad chilena, guarda un estrecho nexo con el imaginario del orden.

"La historia se enseña desde la primaria como Historia y Geografía, porque la idea que la guía es la soberanía sobre un territorio, que la ejerce el Estado, no la soberanía popular, que la ejerce en principio la nación entera" (PNUD 2002: 60).

A la reivindicación de la soberanía popular (el acto de modernidad en que nace Chile), se sobrepone la afirmación de la soberanía nacional, y la importancia del territorio y de las fronteras empieza a desplazar a la voluntad ciudadana. "Se anuncia aquí el vacío de sociedad que tantas veces se esconde tras el protagonismo del Estado" (PNUD 2002: 60-70).

Ya desde la elección de Alessandri y las reformas de 1924-1925, pasando por el primer gobierno de Ibáñez, hasta el frente popular, queda consagrado el imaginario estatal que predomina a lo largo del siglo XX. En todo este período, la convivencia social tiene por referente principal el Estado en sus diversas facetas. "Él es el motor de las estrategias de industrialización y desarrollo económico, así como el propulsor de las reformas sociales (...) El alma estatal de Chile, sería una metáfora de la experiencia de integración social" (PNUD 2002: 61). 
La extensión del imaginario estatal va acompañada de una expansión de lo público. La sociedad se vuelca a un espacio público mediado por el Estado, el que abarca tanto a los partidos políticos y la administración pública, como a los servicios de educación, salud y vivienda. "Incluye la universidad pública y la previsión social, además de la promoción de organizaciones comunitarias" (PNUD 2002: 61)

Sólo en las últimas décadas del siglo XX se observa una ruptura con la construcción político-estatal de un imaginario público desplazado por un imaginario privado. “Tal privatización obedece asimismo a una construcción política” (PNUD 2002: 61).

\section{La pobreza como rasgo tradicional de controlabilidad social en Chile}

Este es un aspecto central en la reflexión sobre las tradiciones. En general, plantear como hipótesis que la pobreza es un rasgo tradicional de nuestra sociedad, de por sí puede generar controversia. En el fondo se afirmaría que la pobreza es producida como medida de orden y control, propio del funcionalismo. Sin embargo, según las fuentes consultadas, el manejo histórico que ha existido respecto al tema de la pobreza, inducen a pensar que tal afirmación no necesariamente es un sinsentido. Esto es producto principalmente, de que siempre ha estado presente en nuestra historia, como un elemento promotor de la armonía social, lo que implica que hay un reconocimiento e identificación de la población hacia ella, su presencia no generaría miedo ni asombro, tal cual plantea Larraín: "La pobreza no surge como un foco potencial de conflicto producto de su larga existencia y de su histórico tratamiento por parte de la clase política" (Larraín 2004: 233).

La pobreza es más bien funcional, ya que su presencia hace que la ciudadanía tenga temor a ella, lo que a la larga facilita el orden y la cohesión social. "La ciudadanía sería proclive a aceptar múltiples procesos de modernización ya que propiciaría una salida a la pobreza”. (Larraín 2004: 233). Según se expone en el PNUD (2002), la pobreza es una tradición, sustentada en una demanda, "el nacionalismo del relato popular aparece como exigencia de pertenencia a lo que se les niega. Pertenencia que no se formula en términos abstractos" (PNUD 2002: 34). 
La acción compulsiva que genera la necesidad de superar la pobreza en la ciudadanía chilena, la hace vulnerable y permanentemente dispuesta a experimentar y aceptar nuevos modelos de desarrollo que prometan la superación de la misma, pero que a la larga no por esto lo cumplen.

Para Morandé (1990), la pobreza en sí no es un mal de la modernidad que afecte a Chile y América Latina, sino que más bien es el resultado de una herencia cultural determinada, llamada economía de subsistencia y la ética del trabajo tributario. Tal visión del trabajo habría limitado el desarrollo del capitalismo en Latinoamérica tal como ocurrió en Europa y los Estados Unidos, pues lo importante no era la acumulación de la riqueza, sino que el esfuerzo y la satisfacción de la ofrenda. A pesar de lo anterior, las élites americanas impusieron modos de producción modernos a partir de la segunda mitad del siglo XIX, lo que alteró notablemente las estructuras productivas coloniales. Sin embargo, la dualidad continuó subterráneamente existiendo, al punto de que hoy en día podemos encontrar economías informales paralelas funcionando en todos los países de nuestro continente:

"La legitimación tributaria y sacrificial del trabajo, la que se expresa en una organización económica dualista que opera monetarizadamente "hacia afuera", integrándose a los mercados internacionales a través de los medios de pago habituales, y no monetarizadamente "hacia adentro". En otras palabras, la economía de subsistencia "hacia adentro" y la economía de exportación "hacia afuera" representan los dos polos que tempranamente se estructuraron en Chile y que se mantienen hasta el día de hoy, aunque con distintas modalidades, como es el caso actual de la cohabitación de un sector exportador altamente competitivo y de un sector de economía informal de baja productividad que abarca casi a la mitad de la población de Chile". (Morandé 1990: 43).

Entonces, para Morandé la pobreza no constituye la enfermedad de la sociedad, sino que más bien es la resultante de un modelo cultural originado en un modo de producción cuyo fin no era la riqueza, sino que la subsistencia, y donde el trabajo se constituye más en una carga obligatoria, que en una forma de consumar la existencia.

Para Bengoa (1996), la pobreza si bien es un factor tradicional, de identidad chilena y latinoamericana, no constituye una estructura 
inmóvil. A su juicio, existen por lo menos dos tipos de pobreza: una heredada del modelo colonial hispánico y arraigada en los campos, y otra (la más perjudicial de las dos) que se origina a partir del propio desarrollo económico. Estos últimos son los pobres "modernos" que forman la fracción de los excluidos permanentes; "lo que hoy se conoce como pobreza dura y que es fruto de generaciones de frustración alimentada por el desarrollo industrial del capitalismo" (Bengoa 1996, 38).

Bengoa señala que los sectores dirigentes latinoamericanos aún no comprenden el hecho de que el crecimiento económico de por sí no soluciona la pobreza, incluso es productor de pobres. De nuevos pobres, diferentes de los que quedaron rezagados en los pueblos, caseríos y campos apartados. En las ciudades principalmente, surgen de la atracción producida por la modernización urbana y también, de modo creciente, por el deterioro de los medios urbanos. Pero la pobreza moderna no es sólo característica de las ciudades, sino también de las actividades agrícolas, mineras y forestales, todas ellas orientadas hacia la exportación, generan nuevos bolsones de pobreza asalariada en las inmediaciones de los centros productivos (Bengoa 1996).

En resumen, según el PNUD (2002), la pobreza tiene un carácter funcional, y se ejerce como acción de control social. Bengoa entiende que la pobreza siempre ha sido un factor constitutivo de la identidad latinoamericana, pero que sin embargo, hoy ha perdido toda dignidad. Incluso el Estado, cuando determina que una zona es de "extrema pobreza", no hace otra cosa que crear un ghetto donde las personas se sienten estigmatizadas dentro de una categoría sin salida.

\section{El autoritarismo y la cultura mestiza}

Al hablar de la cultura mestiza en Chile y Latinoamérica, Morandé niega que el principio fundacional de los pueblos americanos sea la violación de la mujer indígena en manos del conquistador español. Niega la relación amigo-enemigo entre naturales y europeos. Más que choque hay encuentro, y por tanto, no es necesaria una supuesta liberación:

"El mestizo tiene necesariamente que explicarse su propia existencia a partir de ese acontecimiento. No le basta decir abstractamente "yo 
soy heredero de lo mejor de Grecia, del mundo clásico, traspasado por el medioevo cristiano" o decir "yo soy heredero de la grandes culturas de Teotihuacan y Meso América". No, el mestizo está obligado a decir "yo soy hijo del acontecimiento, del encuentro, que está fechado, y por lo tanto mi conciencia histórica surge de la aceptación de la realidad del acontecimiento. Que América Latina sea mestiza no sólo es un hecho; el reconocerlo es también una clave de interpretación de su propia historia" (Morandé 1990:11).

Según este autor, asumir la dialéctica hegeliana en la conquista de América, es superponer una categoría decimonónica a una realidad anterior e infinitamente más compleja. No hubo lucha, sino la aceptación (por parte del mundo indígena) de una catástrofe determinada por el cosmos. Respecto del mestizaje, Morandé rechaza el paradigma de la mujer violada y lo contrasta con el de la ofrenda amistosa:

"Así por ejemplo, en el mundo Guaraní no tendría sentido hablar del mestizaje con la figura de la madre violada, como se plantea Octavio Paz en "El Laberinto de la Soledad". En las sociedades de parentesco eran los jefes de familia quienes entregaban a sus hijas en alianza y así sucedió también con el mestizaje" (Morandé 1991: 50).

Tomando lo anterior como base, para Morandé, el autoritarismo americano surge de una doble vertiente. La primera está determinada por el predominio de la cultura oral por sobre la escrita, lo que a su juicio fomenta la figura del hombre fuerte de discurso paternalista:

"Recuerden a Velasco Ibarra, que fue tantas veces Presidente de Ecuador, y al que derribaron cuatro veces... Él decía "denme un balcón y vuelvo al poder". El poder del carisma de los líderes es algo que ha operado en Chile y que opera en América Latina. El que sabe hablar, crear un espacio de comunicación, tiene una clave para el poder; mucho más que el que dispone del argumento demostrable. Hoy día este poder persuasivo de la palabra se ha potenciado para quienes tienen, junto a este carisma, acceso a la televisión" (Morandé 1990:16).

La segunda vertiente autoritaria se encuentra en los Estados nacionales surgidos a principios del siglo XIX, en los cuales se negó la herencia mestiza y se impuso una mentalidad racionalista extranjera, cuyo origen estaba en la Revolución Francesa, pero que en América 
fue encarnada por gobiernos "Ilustrados", pero claramente elitistas y autoritarios. Bengoa considera al mestizo, como un ser despreciado tanto por los indígenas como por los españoles y criollos, por tanto, forja una identidad a partir de la negación, y con los estigmas y prejuicios provenientes de ambos grupos. Su espacio de asentamiento es la ruralidad, donde históricamente ha estado sometido al poder de los dueños de la tierra, aunque también ha sido el espacio donde ha construido una forma de ser campesina. El campo es la mayor fuente de identidades en Chile, pero a la vez constituye la base del mayor de todos los autoritarismos: el paternalista.

La falta de una cultura democrática es atribuida al hecho de que, por ejemplo, en Chile no se desarrolló una cultura urbana, sino que más bien se trasplantó el campo a la ciudad, con todas sus relaciones de poder: "Muchos de los primeros empresarios no agrarios, se "agrarizaron" apenas lograron enriquecerse. Así lo hicieron los mineros del norte, los del carbón, e incluso familias poderosas del mundo financiero, como los Edwards, que junto con dirigir el periódico más liberal, comercial y representativo de lo que sería una burguesía en Chile, El Mercurio, han presidido las sociedades de criadores de caballos criollos y numerosas actividades relacionadas con la tradición rural" (Bengoa 1996:38).

Incluso, Bengoa liga esta identidad con el gobierno militar que rigió Chile entre 1973 y 1990: "Durante dieciocho años, sin embargo, la voz fuerte, caporal, rural agraria siguió sonando en la política criolla. Aún hoy en día suenan las voces autoritarias de la identidad rural en el concierto discursivo criollo, en los debates de lo que debe ser y lo que no es. La identidad rural autoritaria se saca a relucir como la identidad "natural" de los chilenos" (Bengoa 1996:38).

Para Bengoa, la ciudad y sólo la ciudad, puede generar una identidad diferente fundada en la participación y no en la añorada "comunidad perdida" de los campos.

Comparativamente, ambos autores reconocen la matriz autoritaria en la configuración de nuestra identidad, pero Morandé nuevamente culpa principalmente a las elites y su discurso modernizante, mientras que Bengoa defiende una aplicación más fuerte de la urbanización y los ideales democráticos, culpando a las tradiciones rurales de nuestra tendencia hacia soluciones político-sociales de corte autoritario. 


\section{La tradición de la religiosidad de la sociedad chilena}

La religiosidad, y particularmente la forma de expresarla por parte de los/as chilenos/as, es reconocida también como un rasgo tradicional de nuestra sociedad.

De acuerdo a lo expresado en el PNUD, "los chilenos creen masivamente en la existencia de Dios, o de realidades místicas. La no creencia es minoritaria" (PNUD 2002). Para Larraín (2001) la creencia en alguna religión es lo tradicional, no la iglesia católica en sí misma; sin embargo reconoce en ella, su importante rol institucional y estructural en la conformación de la sociedad, al igual que Garretón (2007), que plantea que su aporte se sustenta en su rol educativo en la ciudadanía, y su permanente vínculo con la clase política. En este último aspecto hay coincidencia entre las distintas fuentes.

Todas consideran a la iglesia católica como una tradición en sí, pero esta tradición se sustenta en el permanente vínculo que ha tenido esta con las elites dominantes, tanto políticas como económicas. Lo que a la larga legitima moralmente el actuar del Estado y de la clase política ante la ciudadanía, según lo plantea Bengoa: "La iglesia católica es y ha sido un elemento aglutinador, pero a la vez coercitivo en ciertos aspectos de las conductas sociales, legitimando muchas veces lo que en un Estado de conciencia real, pareciera ilegitimable" (Bengoa 1996:36).

La religiosidad y particularmente la ligada a la iglesia católica, sería un rasgo tradicional de nuestra sociedad, pero es un rasgo al igual que los anteriores muy peculiar, ya que más que buscar un vínculo entre la ciudadanía y sus raíces, es visto como un elemento legitimador del poder de las elites. El rol del Estado nacional en la conformación y eventual degradación de la identidad, presenta múltiples variables, al igual que el análisis de la influencia de la iglesia católica.

Morandé considera al Estado Nacional decimonónico (heredero de los ideales dieciochescos) como el principal responsable de la alienación de la cultura mestiza barroca surgida en los siglos XVII y XVIII americanos (Morandé 1990): “El Estado nacional es por definición la imposición de una cultura del texto. El Estado dicta 
la Constitución, el Código Penal, el Código Civil, toda la legislación correspondiente. Pero lo novedoso es que aquí a diferencia de Europa se contrapone la cultura del texto a los tres siglos previos de cultura mestiza de la oralidad" (Morandé 1990: 13).

Los Estados Nacionales habrían sentido como misión eliminar todo vestigio de la cultura mestiza barroca, la cual asociaban directamente con España. Ahora todos por igual eran ciudadanos de sus países, no importando si eran parte de pueblos indígenas o sociedades mestizas. Toda diferencia estamental se consideró como un privilegio antidemocrático. El problema es que esto era una América multicultural y no la Europa de las luces. La Iglesia en América, según Morandé, estableció un derecho de gentes que permitía diferenciar identidades y fomentar una convivencia armónica de los distintos pueblos que habitaban el continente. Todos formaban parte de una misma ecúmene, pero como agrupaciones de origen y trato diferenciado.

Concretamente respecto de la Iglesia, Morandé (1991) considera que representa la máxima reserva de identidad latinoamericana, pues a través de ella se generó la fusión mestiza que une lo europeo y lo indígena por medio del rito popular y la veneración mariana. Lo americano se encuentra en la cultura oral y mística que se generó durante el barroco de los siglos XVII y XVIII. Los Estados Nacionales trataron de negar esta identidad, pero ella sobrevivió en la religión mestiza popular. Sólo la Iglesia posee la llave para volver a conducir esta conciencia y entregar una respuesta original al tema de nuestra eterna pregunta sobre los orígenes.

"El barroco, que es propiamente el estilo cultural con el cual se desarrolla la consolidación de América Latina, tenía como idea matriz la de formar una ecúmene universal de pueblos. Esta idea se pierde, en mi opinión, con la Ilustración, y recién se recupera, en el caso de la Iglesia, con el Concilio Vaticano II" (Morandé 1991:50).

Bengoa, por el contrario, no se explaya mayormente sobre el tema de la Iglesia Católica, pues la considera como parte fundamental de la cultura autoritaria de nuestros países, sin embargo, se opone a la religión popular que defiende Morandé, la cual forma parte de la cultura de la dominación impuesta en los campos. Además, piensa que la religiosidad mestiza no es otra cosa que la superposición de símbolos católicos sobre ritos indígenas: esto explicaría la 
importancia del culto mariano en América, como continuación del ritual a la madre tierra (Bengoa 2006).

"Niño, decía la patrona del fundo, anda a avisar a los peones que esta noche rezamos el rosario. Allí llegaban todos, obligados a rezar y cantar:

Un pecado sin cesar me atormenta noche y día,

Ay, Señor del alma mía, que me tengas que salvar...

Se cantó por años, creó costumbre. Venía de España, se adaptó a estas tierras; se hizo parte nuestra, de nuestro mestizaje, de nuestro colorido, de la identidad de los hijos de esta tierra" (Bengoa 1996:37).

\section{La tradición histórica de la búsqueda de la seguridad y el orden de parte de los grupos de poder y de la ciudadanía}

Fundamentalmente se plantea en el PNUD (1998) la tesis de que la sociedad chilena desde su origen y durante toda su historia, se ha construido y sustentado en la búsqueda del orden y de evitar el caos, vale decir, un rasgo distintivo de nuestra idiosincrasia sería el miedo a que las cosas no funcionen y que generen desorden. Esto llevó a la primera elite dirigencial, para conservar la armonía y la estabilidad, a preservar la noción de Estado, según los preceptos occidentales establecidos en la colonia.

La sociedad chilena por tanto, codifica su incertidumbre bajo la forma de un dilema, "orden versus caos", algo que se presentará por los próximos dos siglos.

"La alteración violenta de la paz social y la reinserción social del país, la pérdida de los marcos de referencia habituales y la imprevisibilidad del nuevo rumbo, todo ello genera incertidumbre" (PNUD 1998: 68).

Toda la historia de Chile, puede leerse como una continua tensión entre orden y desorden. El orden se legitima de cara a la amenaza de la anarquía; "precisamente el miedo profundamente arraigado al caos nutre la veneración del orden" (PNUD 1998: 68). Este orden tiene como fin promover el cambio social, un cambio que permitirá 
mayor desarrollo y evolución del país. En Chile, siempre estará en juego la relación orden y cambio:

"Cuanto mayor es la confianza en el orden, mayor es la disposición al cambio; por el contrario, cuando crece el temor al desorden, prevalece la defensa del orden establecido" (PNUD 1998: 69).

La sociedad chilena desde su origen, enfrenta los retos de toda sociedad moderna: ¿Cómo lograr un cambio social, una modernización, sin destruir el orden?

Después de varias revueltas sociales a fines de la década del veinte del siglo XIX, la elite chilena llega pronto a un consenso en torno a la noción de orden. A juicio del informe, este principio fundacional, tiene doble cara (PNUD 1998: 69):

- Institucionalización del orden republicano

- Conservación inalterable del orden heredado

Desde los inicios, se instala una modernidad híbrida, en la cual prevalece la imitación del modelo de desarrollo social precedente y se consolida la colonialidad del poder en base a la lógica occidental. A la vez, coexisten “innovación” y “tradición”, producción deliberada del orden institucional y defensa del orden natural de las cosas: "existe una complementariedad espontánea que descansa sobre el peso de la noche, una inercia que asegura la paz social" (PNUD 1998: 68).

\section{Conclusión}

Respecto al objetivo referido a identificar qué rasgos tradicionales forman parte de la construcción social actual de Chile, podemos decir que en nuestro país como en la mayoría, existen tradiciones, pero éstas no vinculan a la sociedad chilena con sus rasgos endógenos identitarios, sino más bien, son instrumentos de las elites para adaptar y readaptar modelos de desarrollo social a su conveniencia.

Por tanto, las tradiciones de nuestra sociedad actual son más bien tradiciones de las elites, no de la población; éstas si es que existieron, a juicio de Garretón, murieron con la dictadura militar de los años setenta y ochenta, por lo que escenario del advenimiento de la modernización occidental, se hizo favorable. 
Entre los aspectos tradicionales mencionados más relevantes, está en primer término el análisis de la práctica de la imitación a otros modelos de desarrollo exógenos en la construcción de la sociedad chilena. Seguidamente influye el Estado y todo lo que implicó su construcción y legitimidad, también la religiosidad de los chilenos, la superación de la pobreza, el autoritarismo y la búsqueda de la seguridad y el orden.

Respecto a la imitación, se la consideró como una acción fundamental y reiterativa en la formación de la sociedad chilena del siglo XIX, que se mantendría hasta nuestros tiempos actuales. Garretón no comparte del todo esta idea, al plantear que si bien hubo imitación del modelo occidental a la hora de constituir legal y jurídicamente al país, en el tiempo la evolución interna de la sociedad es la que ha determinado su futuro.

En lo relativo al Estado, se considera un elemento tradicional en nuestra sociedad principalmente por el respeto y permanente legitimidad que desde la sociedad civil existe hacia él.

También se describe como un rasgo tradicional la religiosidad de los chilenos, es decir, su forma de expresar la fe, y su mayoritario vínculo con lo divino. Se resalta acá particularmente el rol permanente de la iglesia católica como constructora de la moral social y como un componente vital en el rol formativo de la sociedad. Eso sí, siempre vinculado a las elites de poder.

La superación de la pobreza es entendida como un rasgo tradicional producto de que en la búsqueda del orden y la armonía social, organiza a la sociedad permanentemente en función de perseguir objetivos comunes, principalmente su superación y la satisfacción de las necesidades.

Finalmente, la búsqueda de la seguridad y el orden, que si bien es mencionada explícitamente sólo en el IDH del PNUD (1998), todas las fuentes consultadas hacen referencia a ello, como un elemento distintivo y tradicional de nuestra sociedad, y que a la vez se vincula y agrupa al resto de los elementos tradicionales antes mencionados.

Ahora bien, más allá de esta categorización lo interesante de mencionar es que en su gran mayoría, se considera que las tradiciones que forman o han formado parte de nuestra historia como país, se vinculan de una u otra forma, a los rasgos distintivos de las elites y 
los grupos de poder, con la excepción de un rasgo tradicional que desaparece con la dictadura militar: nos referimos al "actor social activo" y su estrecho vínculo con el Estado, que ha desaparecido y no se vislumbra su vuelta próxima.

Podemos finalmente afirmar por tanto, que Chile sí es un país de tradiciones, pero a diferencia de otros países de la región (Perú, Bolivia, México, Brasil), éstas no nos aferran a nuestros rasgos culturales ni a preservar una identidad esencialista, sino que nos hacen vulnerables a los modelos exógenos, donde la ciudadanía solo debe asumir y adaptarse, como es el caso actual del proceso de modernización que vive el país.

\section{Referencias bibliográficas}

Bengoa, J. (1996). La Comunidad perdida. Ensayos sobre identidad y cultura: los desafíos de la modernización en chile. Santiago, Chile: Ediciones SUR.

Garretón, M. (2005). ¿Como pensar al Chile del Bicentenario? Ponencia presentada en Conferencias Presidenciales de Humanidades. Palacio de La Moneda, 30 de marzo, Santiago, Chile.

Garretón, M. (2007). Distancias que crecen entre la cultura y la fe.

Recuperado el 10 de mayo. De http://www. redescristianas.net/2007/05/28/distanciasque-crecen-entre-la-cultura-y-la-fe-manuelantonio-garreton/

Larraín J. (2001). Identidad Chilena. Santiago, Chile: LOM.

Larraín, J. (1994). La Identidad Latinoamericana: Teoría e Historia. Estudios Públicos, 55.

Morandé, P. (1990). Latinoamericanos: Hijos de un diálogo ritual. Creces $11 / 12$.

PROGRAMA DE LAS NACIONES UNIDAS PARA EL DESARROLLO (1998). Informe de Desarrollo Humano. Las paradojas de la Modernización. Santiago de Chile: AUTOR.

(2002). Informe de Desarrollo Humano. Nosotros los chilenos: Un desafío cultural. Santiago de Chile: AUTOR. 